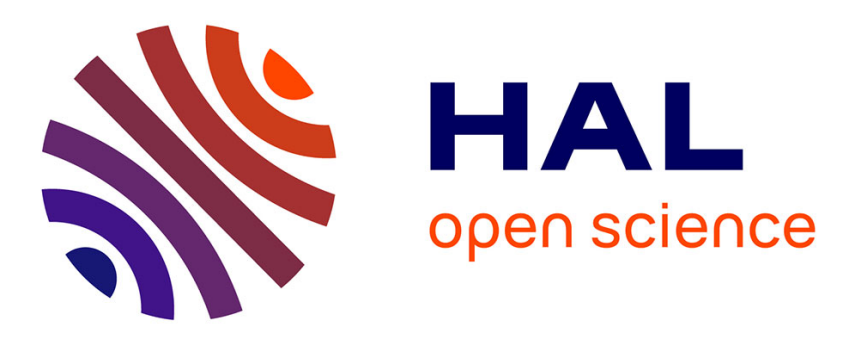

\title{
A stochastic concept for the optimization of manufacturing tolerances in computer aided process plan simulation
}

Said Hamou, Abdelmadjid Cheikh, Jean-Marc Linares, Abdelkader Chikh Daho

\section{To cite this version:}

Said Hamou, Abdelmadjid Cheikh, Jean-Marc Linares, Abdelkader Chikh Daho. A stochastic concept for the optimization of manufacturing tolerances in computer aided process plan simulation. International Journal of Computer Integrated Manufacturing, 2006, 19 (7), pp.663 - 675. 10.1080/09511920500174588. hal-01411126

\section{HAL Id: hal-01411126 \\ https://hal-amu.archives-ouvertes.fr/hal-01411126}

Submitted on 7 Dec 2016

HAL is a multi-disciplinary open access archive for the deposit and dissemination of scientific research documents, whether they are published or not. The documents may come from teaching and research institutions in France or abroad, or from public or private research centers.
L'archive ouverte pluridisciplinaire HAL, est destinée au dépôt et à la diffusion de documents scientifiques de niveau recherche, publiés ou non, émanant des établissements d'enseignement et de recherche français ou étrangers, des laboratoires publics ou privés. 


\title{
A stochastic concept for the optimization of manufacturing tolerances in computer aided process plan simulation
}

\author{
SAID HAMOU*y, ABDELMADJID CHEIKHy, JEAN M. LINARESz \\ and ABDELKADER CHIKH DAHOX \\ yLAT, FSI, Université Abou Bekr Belkaid, B.P. 230, \\ Tlemcen 13000, Algeria \\ zEA(MS)², GMP, IUT d'Aix-en-Provence, Avenue Gaston Berger 13625 \\ Aix-en-Provence cedex 1, France \\ xSERI, 02, Boulevard Pasteur, Tlemcen 13000, Algeria
}

\begin{abstract}
In order to integrate tolerance synthesis for manufacturing dimensions in CAPP systems, an automated process plan simulation module has previously been developed. This module permits the verification of the manufacturing pre-projects and the optimization of the manufacturing dimensions. The module used an optimization procedure which was realized through an equal distribution of the excess tolerance which is that of the design functional requirement. However in reality, this distribution should take into account the stochastic aspects of the dispersions and the complexity or cost of the manufacturing dimensions. In the present work, in order to overcome these drawbacks, a statistical and cost based tolerance synthesis model has been developed. It is shown that this model performs an objective and global distribution of the residual (excess) tolerances of the design functional dimensions on all the manufacturing dimensions of the process plan. The dispersions method is used in the modelling process to determine the variables of the objective function and to automatically extract the manufacturing tolerance chains. These chains are then used to construct the functional constraints of the optimization model. The whole process has been programmed as an automated tolerancing tool for manufacture and validated for several examples.
\end{abstract}

Keywords: Manufacturing tolerances; Process plan simulation; Optimization; Statistical model; Dispersions; CAPP

\section{Introduction}

Industrial products are nowadays appreciated by their quality, their price, their delivery periods and also their availability on the market and all that, in a competing environment. The market pressure and competition are imposing very short development and industrialization cycle times for products. This has led companies to direct their eff orts towards an increase in the eff ectiveness of their design-manufacture process in order to optimize the production cycle of their products. In that order, the use of computer aided design and manufacture (CAD/CAM) systems has brought much in terms of computer power for production time saving and product quality enhancement. Most of these systems have been independently developed mainly in design (CAD) and process planning in manufacture (CAM). Although the automation of mechanical manufacture has reached a very advanced degree, the activity of manufacturing preparation has known limited computer assistance due to the complexity of the formulation of its various tasks. Among the tasks which lend themselves with diffi culty to a complete automation, one

*Corresponding author. Email: hamou_s@yahoo.fr 
finds the process plan simulation which approves or disapproves a process plan draft or pre-project as shown in figure 1. Despite the automation of several activities of manufacture in computer aided process planning (CAPP) systems, very few of them have addressed the aspect of process plan simulation and only some solutions were presented in the literature (Fainguelernt et al. 1986, Weill 1988, Halevi and Weill 1995). In a previous work (Hamou et al. 2004), a module for automating the process plan simulation based on the dispersions method also known as the Dl method was proposed. This module allows on the one hand the verification of the feasibility of the process plan draft or pre-project through tolerance transfer from design to manufacture. On the other hand, it allows the calculation of the optimized manufacturing dimensions using the process dispersions. The optimization of the manufacturing tolerances applied in this automated procedure was performed through an equal distribution of the excess tolerance of the design dimension condition on the individual components of the manufacturing tolerance chain. However in reality, this distribution should take into account the stochastic aspects of the dispersions as well as the complexity and the cost of the dimensions to be processed where the greatest tolerance should be assigned to the most diffi cult dimension to process. In this context, for a more objective distribution of the design excess tolerance, a statistical tolerance synthesis model for the manufacturing dimensions is developed and presented in this paper. The dispersions method is used to automatically identify the variables of the objective function and to automatically extract all the manufacturing dimension chains to build the constraints for the tolerance optimization model.

\section{Process plan simulation using the $D$ l method}

The simulation of the process plan (PP) pre-project is a very significant stage in the manufacturing process of an

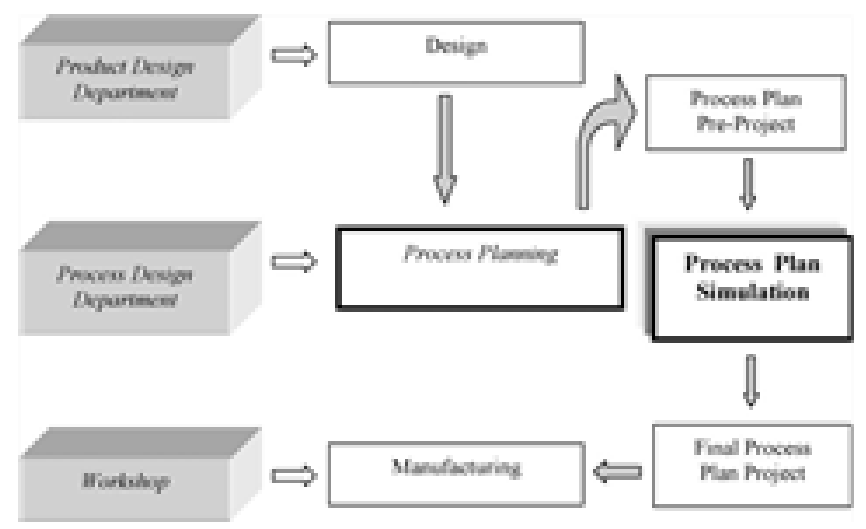

Figure 1. Position of the PP simulation in design and manufacture. industrial product. It permits the feasibility of the process plan to be checked for all the functional design dimensions (CBE) and process chip dimensions (CBM) and to calculate the optimized manufacturing dimensions. In the literature, there are two popular methods used to simulate the process plan pre-project, the vectorial method and the Dl method (Marty and Linares 1994). The latter is more effi ciently programmable than the manual vectorial method. In a previous work (Hamou et al. 2004), we have proposed a process plan simulation based on the Dl method constructed in the form of three procedures in a given chronological order. Based on the minimal transfer method (Duret 1981), a first procedure performs the verification of the process plan drafts represented in a dispersions matrix format. Then, a second procedure performs an equal optimization of the dispersions. Finally, a third procedure computes the optimized manufacturing dimensions. In the present work, the verification procedure is reformulated so that it can automatically identify all the manufacturing dimensions which have an eff ect on the design (CBE) including the process minimal chip (CBM) dimensions. In the same way, it allows the determination of the manufacturing tolerance chains from the dispersions matrix obtained by the minimal transfer method (Hamou et al. 2004). To illustrate these stages of identification and calculation, we take the application example of the process plan pre-project of figure 2. This figure shows the design dimension and process dimension specifications, the

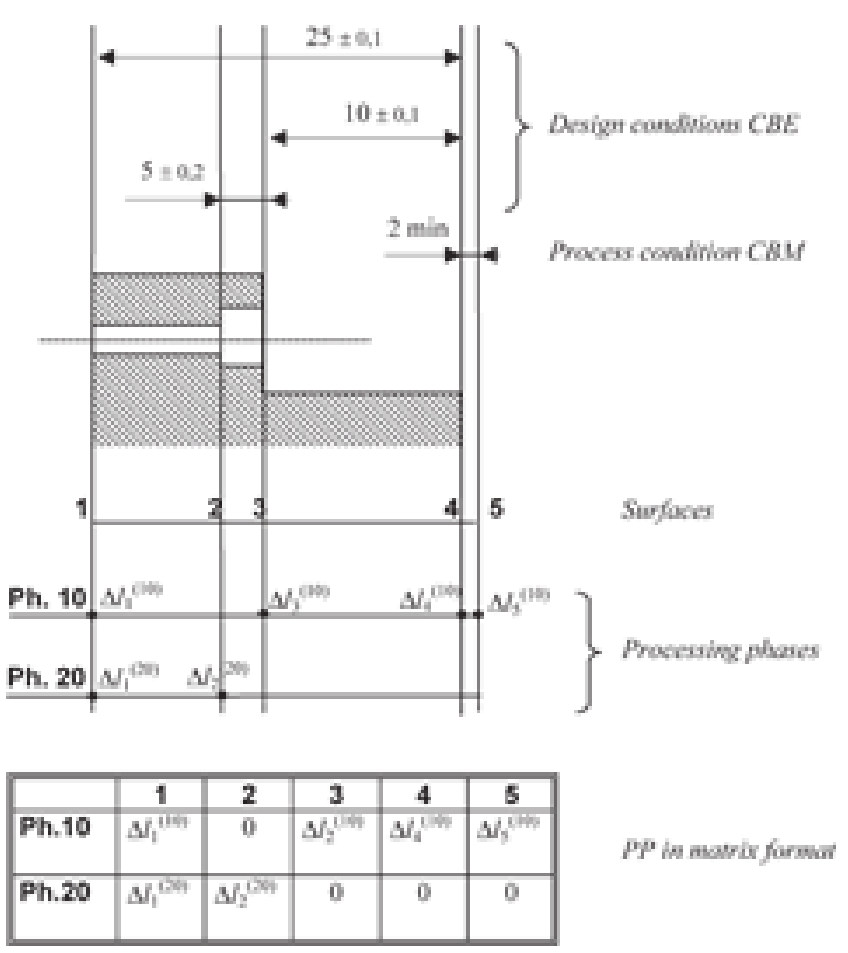

Figure 2. Application example of a PP pre-project. 
manufacturing process operations or phases, the localization graph of dispersions and the matrix representation of the process plan pre-project. In this matrix the columns represent the surfaces and the lines represent the phases. The matrix contains a dispersion element only when a surface intervenes in a phase as a machined surface or as a positioning surface (Hamou et al. 2004). Otherwise the value is set to zero.

Contrary to the vectorial method where it is the process engineer who proposes a whole set of manufacturing dimensions which constitute the process plan, we can show that the Dl method can automatically determine all the manufacturing dimensions (CF). Hamou et al. (2004) have shown that during the verification procedure of the design and process specifications using the Dl method, a minimal transfer condition is reached. This condition is satisfied by the presence, in the matrix representation of the process plan, of zero Dl or two Dl per column except for surfaces that are limits to the design dimension (CBE) or process dimension (CBM). Once this condition is fullfilled, the manufacturing dimensions $(\mathrm{CF})$ which participate in the processing of the design or process dimensions are given by those delimited by surfaces which contain two dispersions present on the same phase. Thus, by applying this identification procedure, we obtain all the dimensions (CF) necessary to process all the dimensions (CBE) and (CBM) in the process plan.

The identification process is best illustrated for the design dimension $\mathrm{CBE}_{2-3} 1 / 45+0,2$ of figure 2 . From the preproject matrix obtained at the minimal transfer state given by table 1 , it is noticed that for phase 10 , there are two dispersions $\mathrm{Dl}_{1}^{(10)}$ and $\mathrm{Dl}_{3}^{(10)}$ stationed on surfaces 1 and 3 . Then, the manufacturing dimension $\mathrm{CF}$ which takes part in the processing of the design dimension $\mathrm{CBE}_{2-3}$ in this phase is $\mathrm{CF}_{1-3}$. Likewise for phase 20, the manufacturing dimension $\mathrm{CF}$ taking part is $\mathrm{CF}_{1-2}$. In other words the manufacturing tolerance stackup for this dimension $\mathrm{CBE}_{2-3}$ is given by the summation of all dispersions in the matrix as follows:

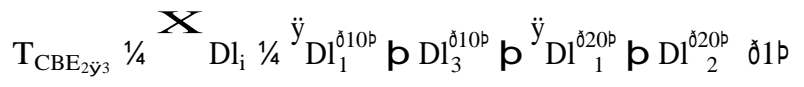

This relation is generalized for any design dimension CBE by the summation of the dispersions of the departure surface $i_{d}$ and the arrival surface $i_{a}$ for every phase $p$ as follows:

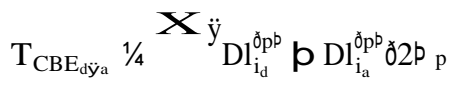

On the other hand the tolerance of every manufacturing dimension $(\mathrm{CF})$ is given by the summation of the dispersions of the delimiting surfaces $i_{d}$ and $i_{a}$ on each phase $\mathrm{p}$ as follows:

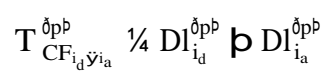

Substituting equation (3) into equation (1) gives the manufacturing tolerance chain for the example design dimension $\mathrm{CBE}_{2-3}$ as follows:

$$
\mathrm{T}_{\mathrm{CBE}_{2 \ddot{y} 3} 1 / 4} \mathrm{~T}_{\mathrm{CF}_{1 \ddot{y} 3}} \mathrm{p} \mathrm{T}_{\mathrm{CF}_{1 \ddot{y} 2}}
$$

Substituting equation (3) into equation (2) gives all the manufacturing tolerance chains in the process plan without the need for a graphical analysis, as follows:

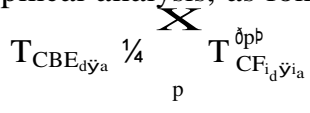

Equation (5) is applied to extract the manufacturing tolerance chains for the functional design dimensions $(\mathrm{CBE})$ and process dimensions (CBM) from the pre-project matrices at the minimal transfer condition. Table 2 gives the manufacturing tolerance chains obtained for the sample example of figure 2 .

As shown with the sample example, the task of the identification of all the manufacturing dimensions (CF) and the extraction of all the manufacturing tolerance chains using the process plan pre-project matrices is automated and programmed as given by the flow chart of figure 3 . The identification and extraction process is integrated in the previously developed procedure (Hamou et al. 2004) for the verification of the process plan pre-projects. The identified manufacturing dimensions (CF) and the extracted manufacturing tolerance chains are needed in the subsequent procedures of tolerance optimization synthesis and computation of the optimized manufacturing dimensions. These procedures have been previously programmed (Hamou et al. 2004) in a process plan simulation module as given in figure 4 . The simulation module is updated so that it can handle an automated identification of the manufacturing dimensions (CF) and extraction of the manufacturing tolerance chains. In order to overcome

Table 1. Minimal transfer condition for dimension $5+0,2$.

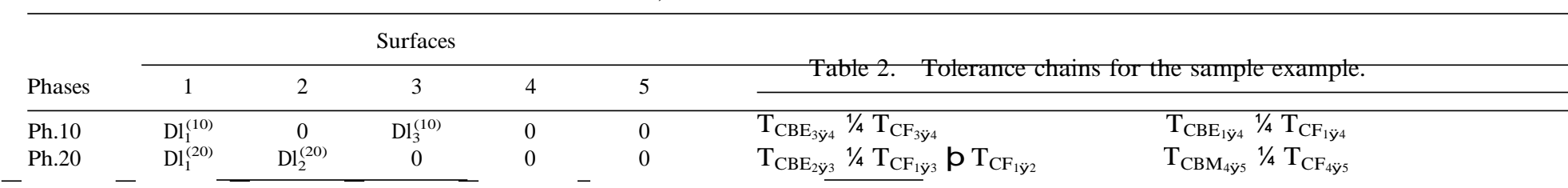




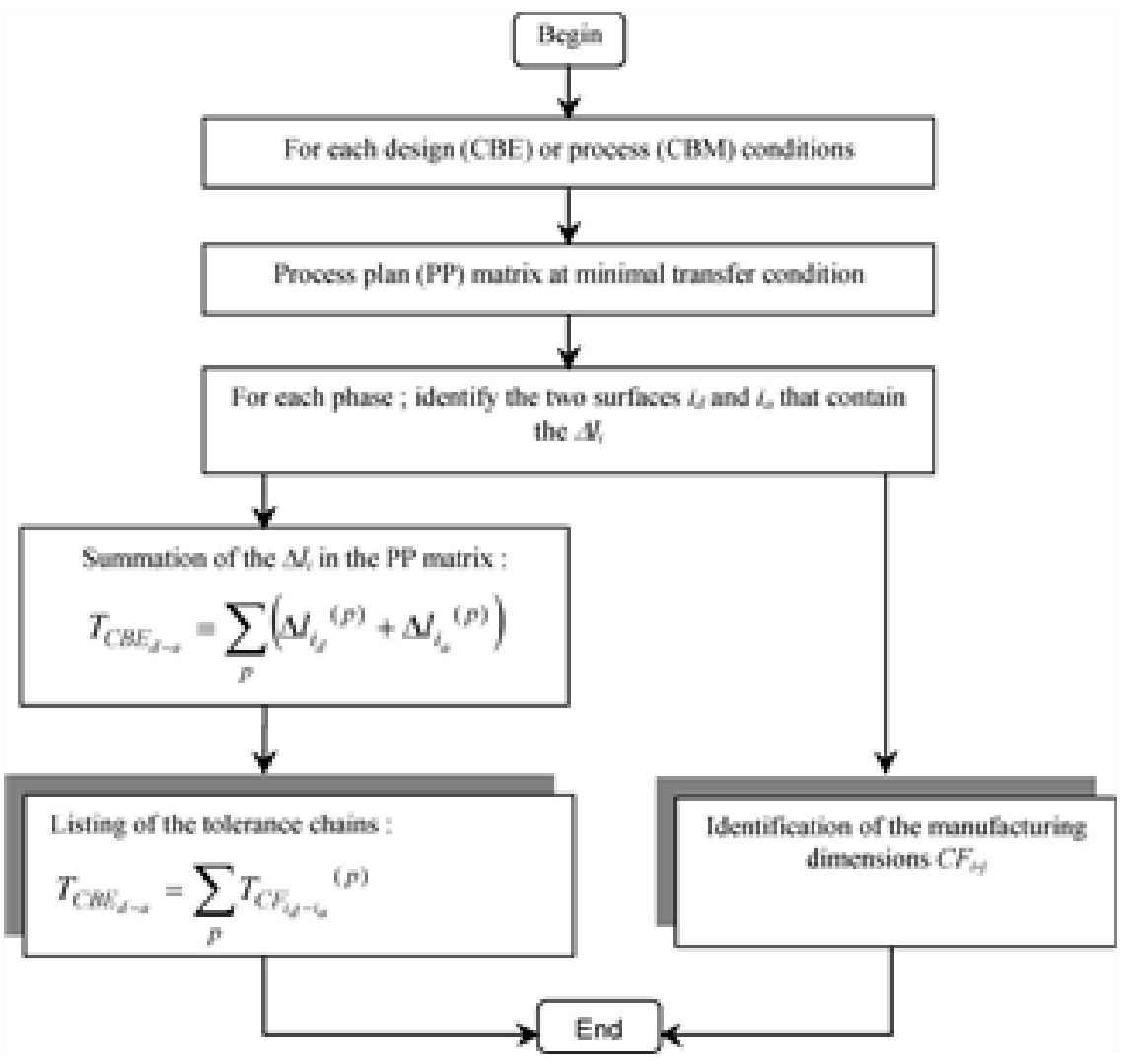

Figure 3. Automated extractions of dimension and tolerance chains.

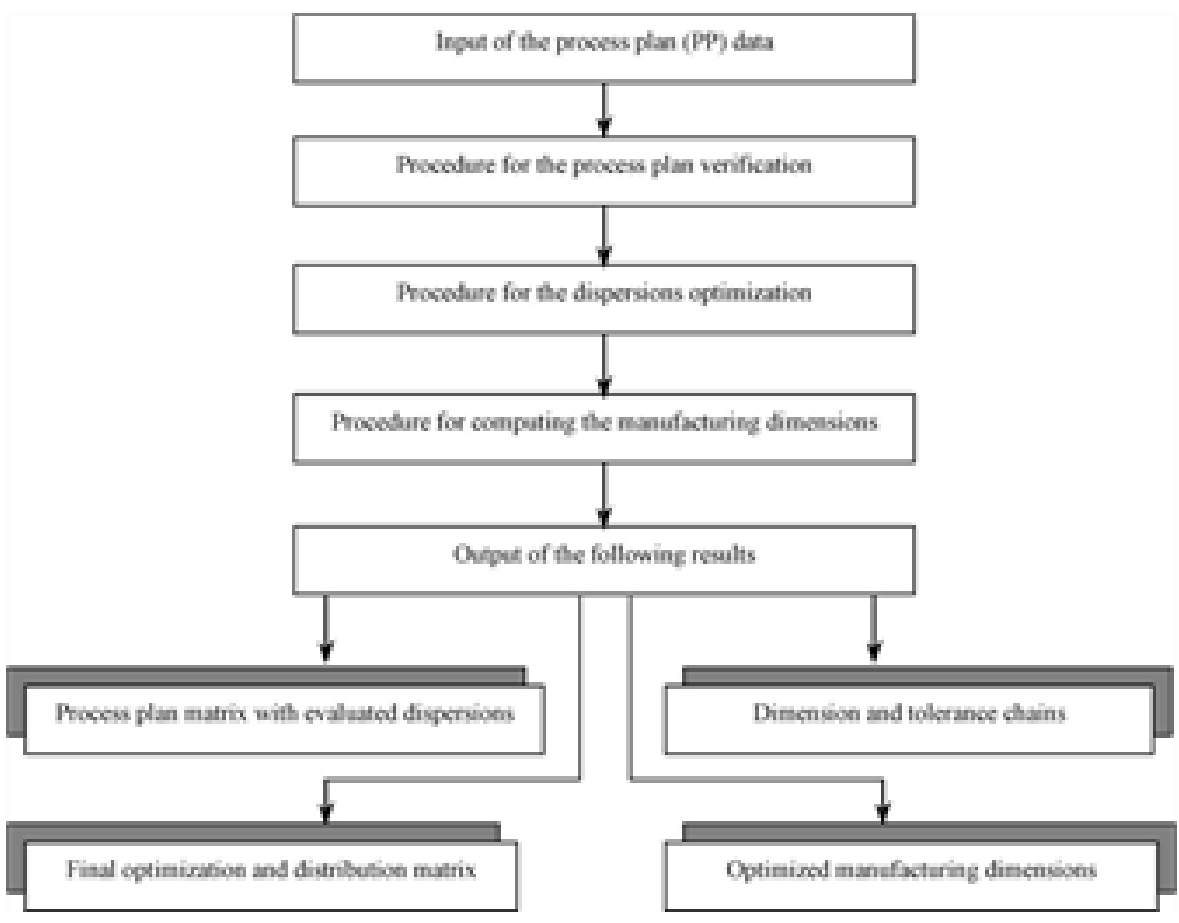

Figure 4. General flowchart of the simulation. 
the drawbacks of equal distribution of excess design tolerance, the chains are used to build a mathematical model for the optimization and statistical synthesis of manufacturing tolerances.

\section{Statistical tolerance synthesis model}

In the previous simulation module (Hamou et al. 2004), the optimization of the manufacturing tolerances was performed through an equal distribution of the excess design tolerance among the manufacturing dimensions (CF) of the chain. However in reality, this distribution should take into account parameters such as the stochastic aspects of the machining dispersions as well as the complexity and the cost of the dimensions to be processed. To satisfy this objective, the arithmetic model for the tolerance chain given by equation (5) is reformulated into a statistical model which will assign the bigest tolerance to the most diffi cult dimension to machine.

\subsection{Arithmetic model}

Once the process plan pre-project has been checked for all the functional conditions $\mathrm{T}_{\mathrm{CC}}$ of the design dimensions (CBE) or the process dimensions (CBM) using equation (6), the process plan becomes a project of manufacture. It is then possible to optimize the dispersions aff ecting the manufacturing dimensions by increasing the values of the dispersions until equation (7) is satisfied for all the manufacturing tolerance chains.

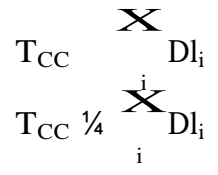

Since the manufacturing tolerances are the resultant of the dispersions aff ecting the delimiting surfaces of each manufacturing dimension (CF), the arithmetic model is given from equation (7) and equation (5) as follows:

$$
\mathrm{T}_{\mathrm{CC}_{\mathrm{j}}}{ }_{\mathrm{i}^{1 / 41}}^{\mathrm{x}} \mathrm{T}_{\mathrm{CF}_{\mathrm{i}}}
$$

Where $T_{\mathrm{CC}_{j}}$ denotes in general the tolerance $\mathrm{T}_{\mathrm{CBE}}$ of the functional design dimension $(\mathrm{CBE})$ or tolerance $\mathrm{T}_{\mathrm{CBM}}$ of the functional process dimension $(C B M)$ and $n_{j}$ denotes the number of tolerance components in the manufacturing tolerance chain $\mathrm{j}$.

\subsection{Statistical model}

Assuming that all the components making up the manufacturing dimension chain (functional design dimension and manufacturing dimensions) are independent and normally distributed, the statistical model given by equation (9) can be used. This equation which is obtained by applying the statistical parameter variance to the manufacturing dimension chain, gives the relation between the standard deviation $\mathrm{s}_{\mathrm{CC}_{\mathrm{j}}}$ of the functional dimensions $\mathrm{j}$ and the standard deviation $\mathrm{s}_{\mathrm{CF}_{\mathrm{i}}}$ of the manufacturing dimensions i within the chain.

$$
\mathrm{s}_{\mathrm{C} \mathrm{C}_{\mathrm{j}}{ }^{1 / 4}}^{\mathbf{X}} \mathrm{s}_{\mathrm{C} \mathrm{F}_{\mathrm{i}}}^{2}
$$

Introducing the coeffi cient $\mathrm{K}$ representing the probability of having a dimension within the tolerance interval $\mathrm{T}$, we can write:

$$
\mathrm{T}_{\mathrm{CC}_{\mathrm{j}}}{ }^{1 / 4} \mathrm{~K}_{\mathrm{CC}_{\mathrm{j}}} \mathrm{s}_{\mathrm{CC}_{\mathrm{j}}} ; \quad \mathrm{T}_{\mathrm{CF}_{\mathrm{i}}}{ }^{1 / 4} \mathrm{~K}_{\mathrm{CF}_{\mathrm{i}}} \mathrm{s}_{\mathrm{CF}_{\mathrm{i}}} \quad \text { } \quad \text { 10p }
$$

Replacing $\mathbf{S}_{\mathrm{CC}_{\mathrm{j}}}$ and $\mathbf{S}_{\mathrm{CF}_{\mathrm{i}}}$ from equations (10) into equation (9) gives the following general statistical model for the manufacturing tolerance chain:

$$
\begin{aligned}
& \mathrm{T}_{\mathrm{CC}^{\mathrm{j}}}{ }^{2}{ }_{1 / 4} \stackrel{\mathrm{n}_{\mathrm{j}}}{\boldsymbol{X}} \mathrm{T}^{\mathrm{CF}_{\mathrm{i}}{ }^{2}}
\end{aligned}
$$

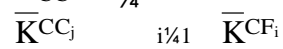

In manufacturing practice $\mathrm{K}$ is equal to 6 (Tinel and Dardy, 1991) which will give from equation (11) the following root sum squares (RSS) statistical model:

$$
\mathrm{T}_{\mathrm{CC} j}^{2}{ }_{\mathrm{i}^{1 / 41}}^{\mathbf{X}} \mathrm{T}_{\mathrm{CF}_{\mathrm{i}}}^{2}
$$

\subsection{Manufacturing cost based tolerance synthesis model}

The manufacturing tolerance allocation problem is a matter of manufacturing cost as well as of function and process capability. In fact, the compiled cost-tolerance data in the literature (Peat 1968) such as the one given in figure 5 reflects clearly the existing relationship between cost and manufacturing tolerance. Based on the cost tolerance data presented in this figure, an approach which adequately describes the relationship between tolerance and associated cost is used (Cheikh 1998). It is evident from this figure that the cost-tolerance curve is strongly concave when drawn as a function of the square of the tolerance. As outlined in figure 6 , the cost curve for each manufacturing dimension is approximated by a set of small linear segments. The objective function which is the sum of concave functions leads to the formulation of a linear programming problem as can be seen later.

Based on the model of figure 6 , let $V_{i k}$ be the slope of the linear segment $\mathrm{k}$ in the cost-tolerance curve $\mathrm{C}_{\mathrm{i}} \mathrm{\partial T}_{\mathrm{C} F_{\mathrm{ik}}}^{2} \mathrm{p}$ when $\mathrm{T}_{\mathrm{CF}}^{2} 2 / 2 \mathrm{~T}_{\mathrm{CF}}^{2} ; \mathrm{T}_{\mathrm{CF}}^{2} \mathrm{~F}_{\mathrm{ik} / \mathrm{1}} \mathrm{s}$ for the manufacturing dimension $\mathrm{i}$; where $k 1 / 41,2, \ldots, l_{i}\left(l_{i}\right.$ : number of segments $k$ for dimension $\mathrm{i}$ ). $\mathrm{T}_{\mathrm{CF}}^{2}$ is replaced by the unit tolerance variables $\mathrm{X}_{\mathrm{ik}}$ defined as $\mathrm{X}_{\mathrm{ik}} 20 ; \mathrm{T}_{C F_{\text {ik }}} \ddot{\mathrm{y}} \mathrm{T}_{C F_{\mathrm{ik} \ddot{1} 1}} \dot{S}$ and if $\mathrm{X}_{\mathrm{ik}} 40$ then $X_{\text {is }} 1 / 4 \max \partial X_{\text {is }} p 1 / 4 T_{\text {is }}^{2} \ddot{y} T_{\text {is } \ddot{y} 1}^{2}$ for every s such as $s 5 k$. 


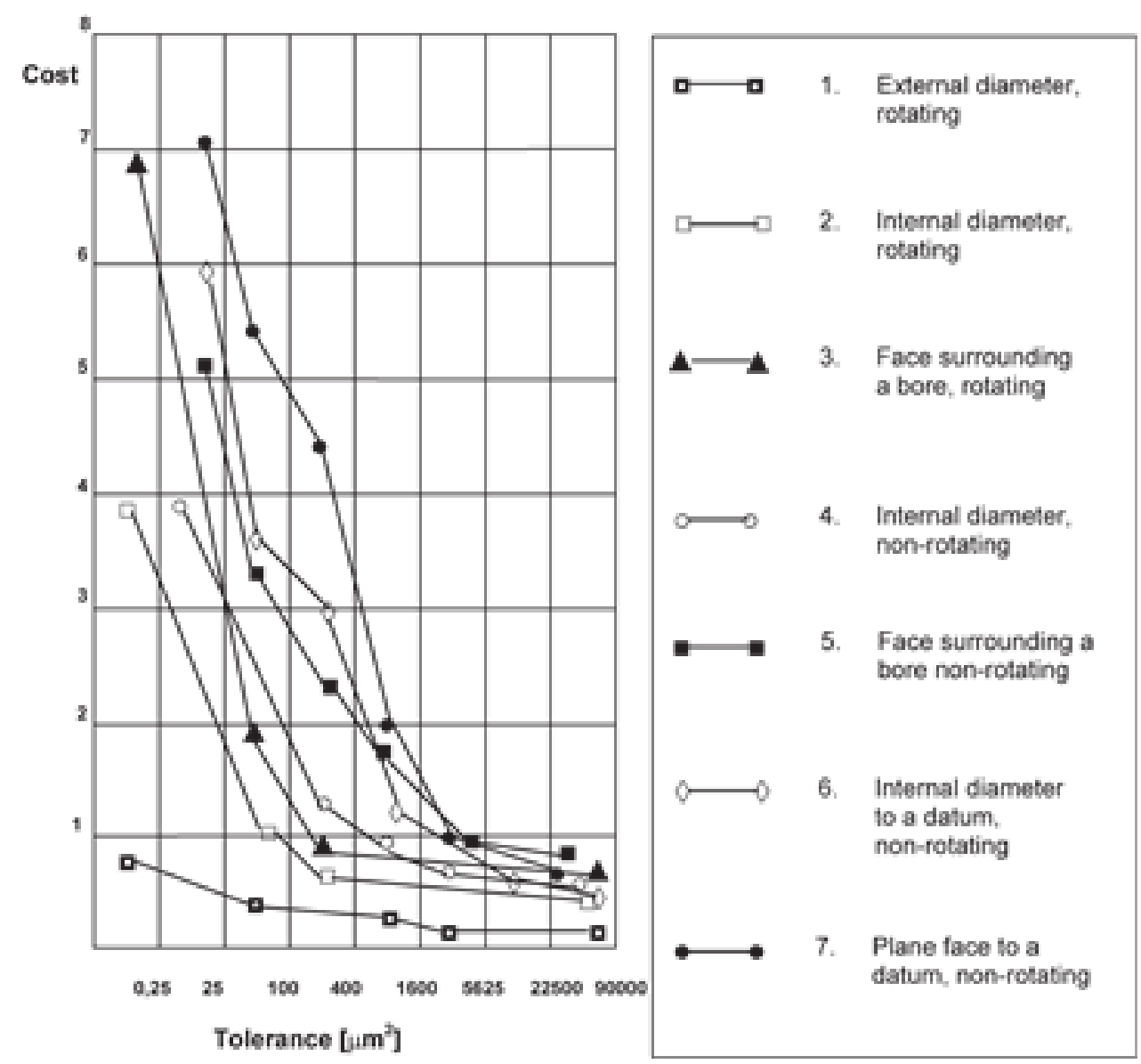

Figure 5. Cost-tolerance database.

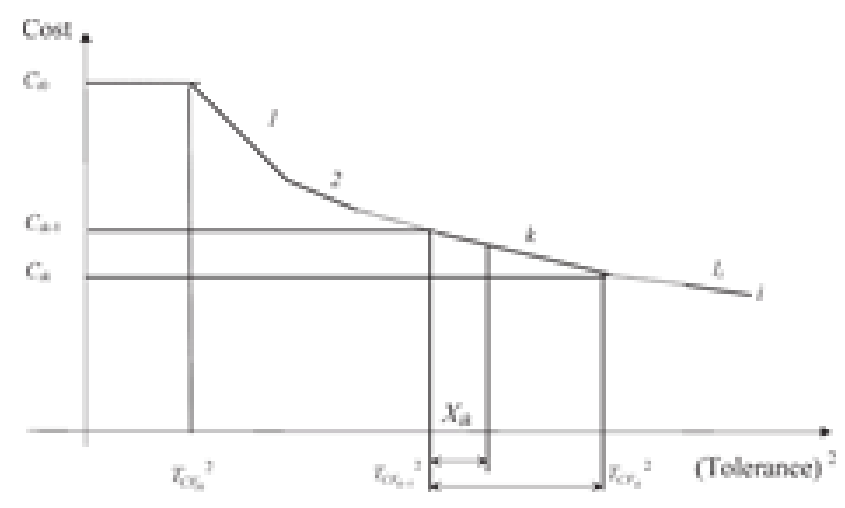

Figure 6. Cost-tolerance model.

The tolerance and corresponding cost for the manufacturing dimension $\mathrm{CF}_{\mathrm{i}}$ are given by the following relations:

$$
\begin{array}{lll}
\mathrm{T}_{\mathrm{CF}_{\mathrm{i}}}^{2}{ }^{1 / 4} \mathrm{~T}_{\mathrm{CF}_{\mathrm{i} 0}}^{2} \mathrm{P}_{\mathrm{k}^{1 / 41}}^{\mathrm{X}} \mathrm{X}_{\mathrm{ik}} ; & 8 \mathrm{i} & \\
\mathrm{C}_{\mathrm{i}} 1 / 4 \mathrm{C}_{\mathrm{i} 0} \mathrm{P}_{\mathrm{k}^{1 / 41}}^{\mathrm{X}} \mathrm{V}_{\mathrm{ik}} \mathrm{X}_{\mathrm{ik}} ; \quad 8 \mathrm{i} & \delta 14 \mathrm{p}
\end{array}
$$

where the $\mathrm{V}_{\mathrm{ik}}$ slopes are computed as follows:

$$
\mathrm{V}_{\mathrm{ik}} 1 / 4 \frac{\mathrm{C}_{\mathrm{ik}} \ddot{\mathrm{y}} \mathrm{C}_{\mathrm{ik} \ddot{y} 1}}{\mathrm{~T}_{\mathrm{CF}_{\mathrm{ik}}}^{2} \ddot{\mathbf{y}} \mathrm{T}_{\mathrm{CF}_{\mathrm{ik} \ddot{y} 1}^{2}}^{2}}-8 \mathrm{i} ; \mathrm{k}
$$

The application of equations (13) and (14) to all the manufacturing dimensions aff ecting a functional dimension condition i.e. a manufacturing dimension chain, gives the following tolerance synthesis model for a dimension chain $\mathrm{j}$ : minimize

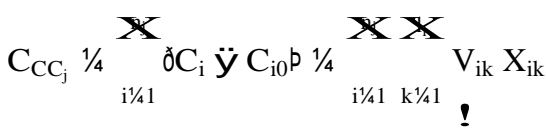

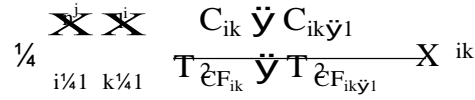

subject to

$$
\begin{aligned}
& \underset{\mathrm{i}^{1 / 41} \mathrm{k}^{1 / 41}}{\mathbf{X}} \underset{\mathrm{X}_{\mathrm{k}}}{\mathrm{T}_{\mathrm{CC}_{\mathrm{j}}}^{2} \ddot{\mathbf{y}}} \stackrel{\mathrm{i}_{\mathrm{i}^{1} / 41}^{\mathrm{X}}}{\mathrm{T}_{\mathrm{CF}_{\mathrm{i} 0}}^{2}}
\end{aligned}
$$

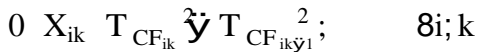


This optimization model represents a linear programming problem which is solved for the unit tolerance variables $X_{\mathrm{ik}}$ using the simplex technique (Murty 1983). The model can be separately applied to all the manufacturing tolerance chains $\mathrm{j}$ within the process plan preproject in order to distribute the functional design tolerance $\mathrm{T}_{\mathrm{CC}_{\mathrm{j}}}$ among the manufacturing tolerances $\mathrm{T}_{\mathrm{CF}_{\mathrm{i}}}$ which are computed from the optimized variables $X_{\mathrm{ik}}$ using equation (13). However a number of these manufacturing tolerances are common to several tolerance chains that the process plan simulation module must take into account during the tolerance synthesis. Dong and Soom (1994) proposed a solution applied to the design dimension chains where several dimensions are common to several dimension chains within a mechanical assembly. This solution is perfectly adaptable to the case of the manufacturing dimension chains. If there are $\mathrm{w}$ dimension chains within the process plan, each dimension chain $\mathrm{j}$ can have $\mathrm{n}_{\mathrm{j}}$ manufacturing dimensions where $\mathrm{m}_{\mathrm{j}}$ dimensions are common to the other chains. This will result in the following tolerance chains:

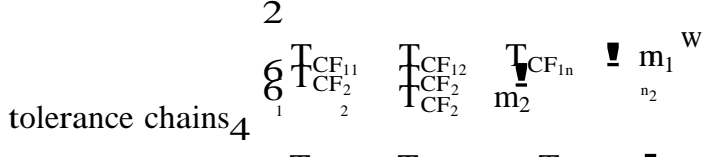

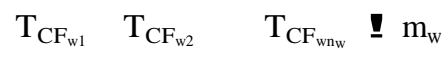

In the process plan there will be $\mathrm{m}$ manufacturing dimensions common to two or more manufacturing chains; $\mathrm{m}$ is given then by:

$$
\mathrm{m}^{1 / 4} \mathrm{~m}_{1} \backslash \mathrm{m}_{2} \backslash \backslash \mathrm{m}_{\mathrm{w}}
$$

Taking into account the fact of common manufacturing dimensions to several dimension chains and in order to perform the optimization procedure to the whole process plan, the final tolerance synthesis model to be integrated in the process plan simulation is reformulated as follows:

minimize

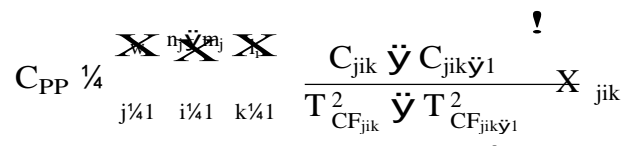

$$
\begin{aligned}
& \text { ! } \\
& \mathrm{p}_{\mathrm{t}^{1 / 41} \mathrm{k}^{1 / 41}}^{\mathrm{X}} \frac{\mathrm{C}_{\mathrm{tk}} \ddot{\mathrm{y}} \mathrm{C}_{\mathrm{tk} \ddot{\mathrm{y}} 1}}{\mathrm{~T}_{\mathrm{CF}_{\mathrm{tk}}}^{2} \ddot{\mathrm{y}} \mathrm{T}_{\mathrm{CF}_{\mathrm{tk} \ddot{1} 1}}^{2}} \mathrm{X}_{\mathrm{tk}}
\end{aligned}
$$

subject to

$$
\begin{aligned}
& \underbrace{n_{k^{1} / 41}^{m_{j}}}_{i^{1} / 41} \underset{X_{j i k}}{ } P_{t^{1 / 41} \quad k^{1 / 41}}^{X} X_{t k}
\end{aligned}
$$

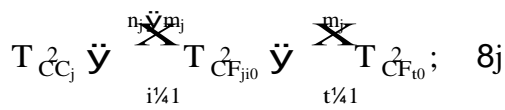

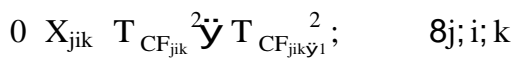

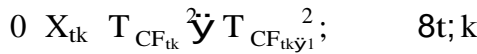

This tolerance synthesis model is built as a linear programming based optimization model (Murty 1983). The optimization process computes the unit tolerance variables $\mathrm{X}_{\mathrm{jik}}$ and $\mathrm{X}_{\mathrm{tk}}$. The computed unit variables $\mathrm{X}_{\mathrm{jik}}$ are then used to determine $T_{\mathrm{CF}_{\mathrm{ji}}}$ the individual tolerances for the manufacturing dimensions $\mathrm{i}$ in each dimension chain $\mathrm{j}$ in the process plan from equation (13) using the following relation:

$$
\mathrm{T}_{\mathrm{CF}_{\mathrm{ji}}}^{2} 1 / 4 \mathrm{~T}_{\mathrm{CF}_{\mathrm{ji} 0}}^{2} \mathrm{P}_{\mathrm{k}^{1 / 41}}^{\mathbf{X}} \mathrm{X}_{\mathrm{jik}} ; \quad 8 \mathrm{j} ; \mathrm{i}
$$

On the other hand, the computed unit variables $X_{t k}$ are used to determine $T_{\mathrm{CF}_{\mathrm{t}}}$ the tolerances of the manufacturing dimensions common to two or more dimension chains in the process plan from equation (13) using the following relation:

$$
\mathrm{T}_{\mathrm{CF}_{\mathrm{t}}}^{2} 1 / 4 \mathrm{~T}_{\mathrm{CF}_{\mathrm{t} 0}}^{2} \mathrm{p}_{\mathrm{k}^{1 / 41}}^{\mathrm{X}} \mathrm{X}_{\mathrm{tk}} ; \quad 8 \mathrm{t}
$$

4. Test and model integration in the process plan simulation

The developed statistical tolerance synthesis model has been programmed into the tolerance optimization procedure of the process plan simulation module as illustrated in figure 7. This figure clearly shows that on one side, the model functional constraints are given from the automatically extracted manufacturing dimension chains. On the other side the cost-tolerance objective function is constructed using the automatically identified manufacturing tolerances $\mathrm{T}_{\mathrm{CF}_{\mathrm{i}}}$ and the cost-tolerance data of figure 5 .

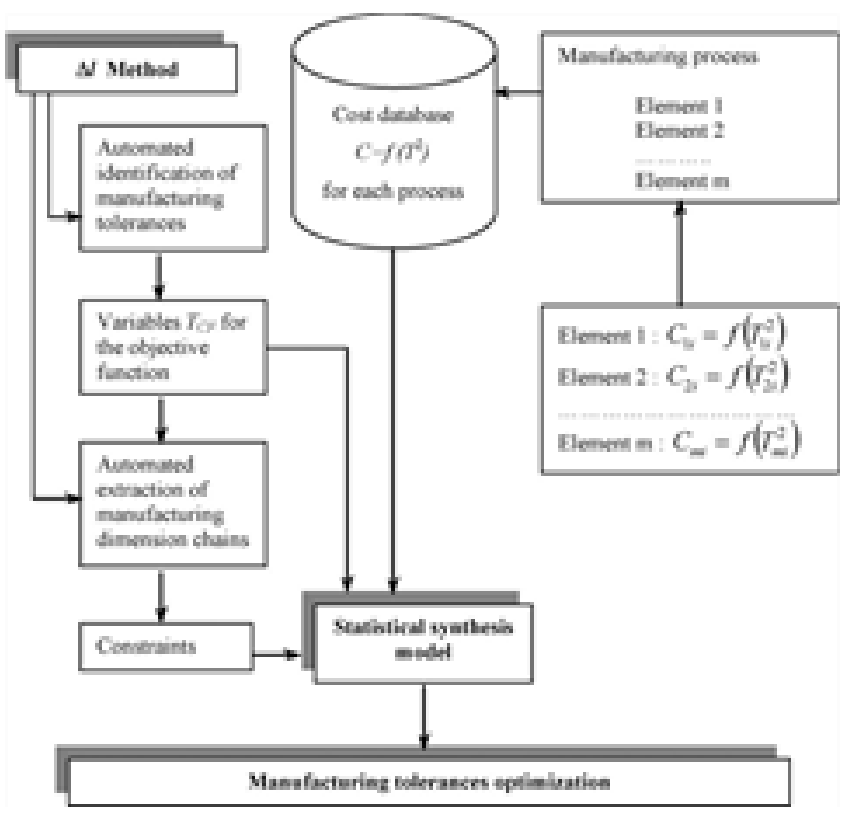

Figure 7. Flowchart of the optimization procedure. 
The tasks of chain extraction and tolerance identification are performed using the dispersions (Dl) method during the verification procedure of the simulation module as previously explained in figure 3. The statistical tolerance synthesis model has been tested on the sample example of figure 1. The screen of figure 8 gives the results for this example of the simulation module based on the D1 method. The screens of figure 9 show the results of the simulation module based on the newly developed statistical tolerance synthesis model. Table 3 gives a comparison of the results given by both the previously developed optimization using the dispersions method and the newly developed synthesis model based on linear programming. These results show that the new optimization procedure performs a better tolerance distribution in adequacy with the type of manufacturing dimensions since they are obtained using diff erent manufacturing processes and diff erent settings. Moreover these tolerances are increased taking into account the statistical aspects of tolerance stack up in the manufacturing dimension chains. The optimization procedure has been integrated in a computer aided process plan simulation module, has been run on several complicated examples and has given similar results to the sample example.

It is worthy to notice that opposite to the previous procedure where the tolerances were optimized and fixed by processing separately the manufacturing dimension chains depending on a computed weight order, the new procdure

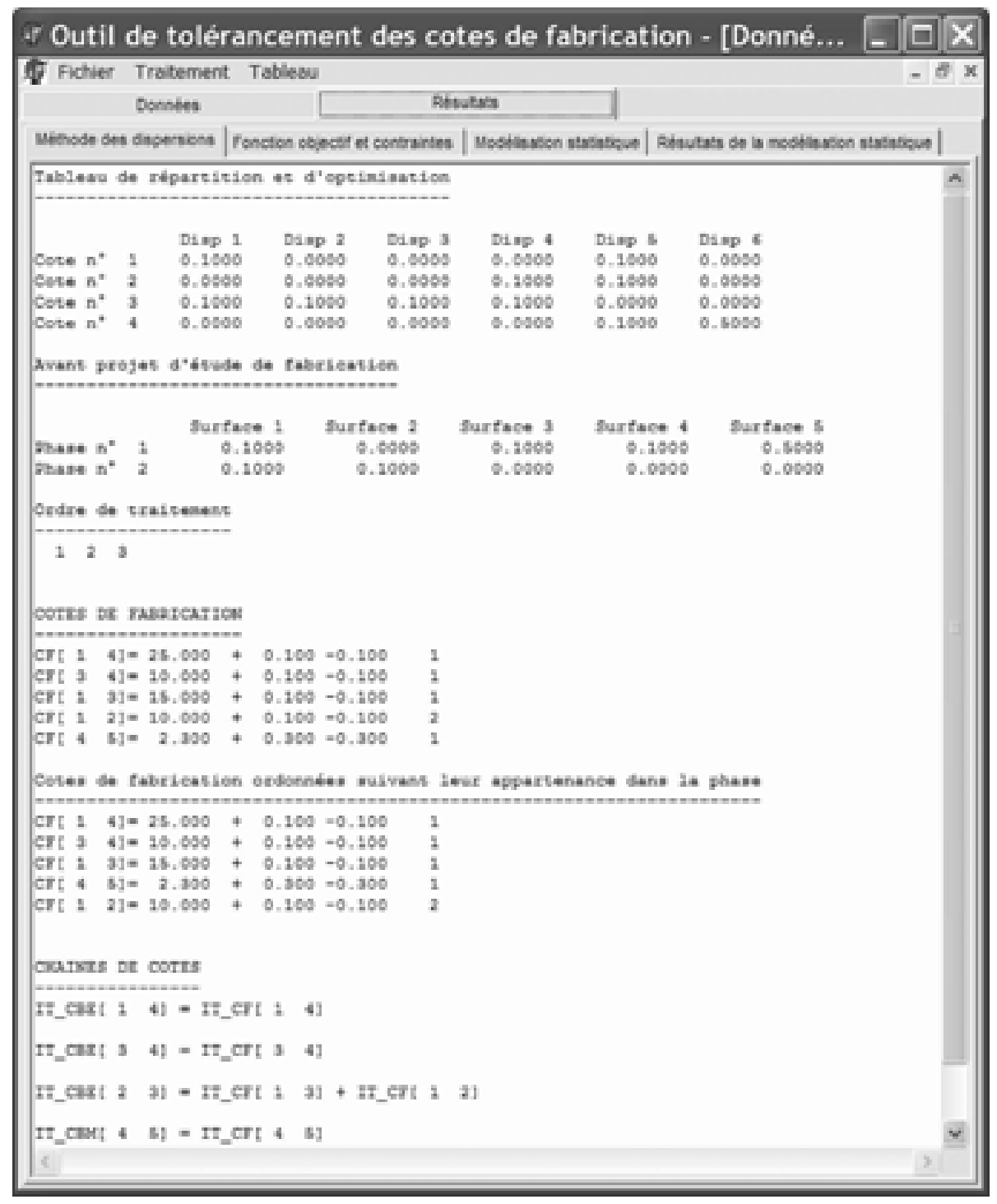

Figure 8. Tolerance optimization using the Dl method for the sample example. 


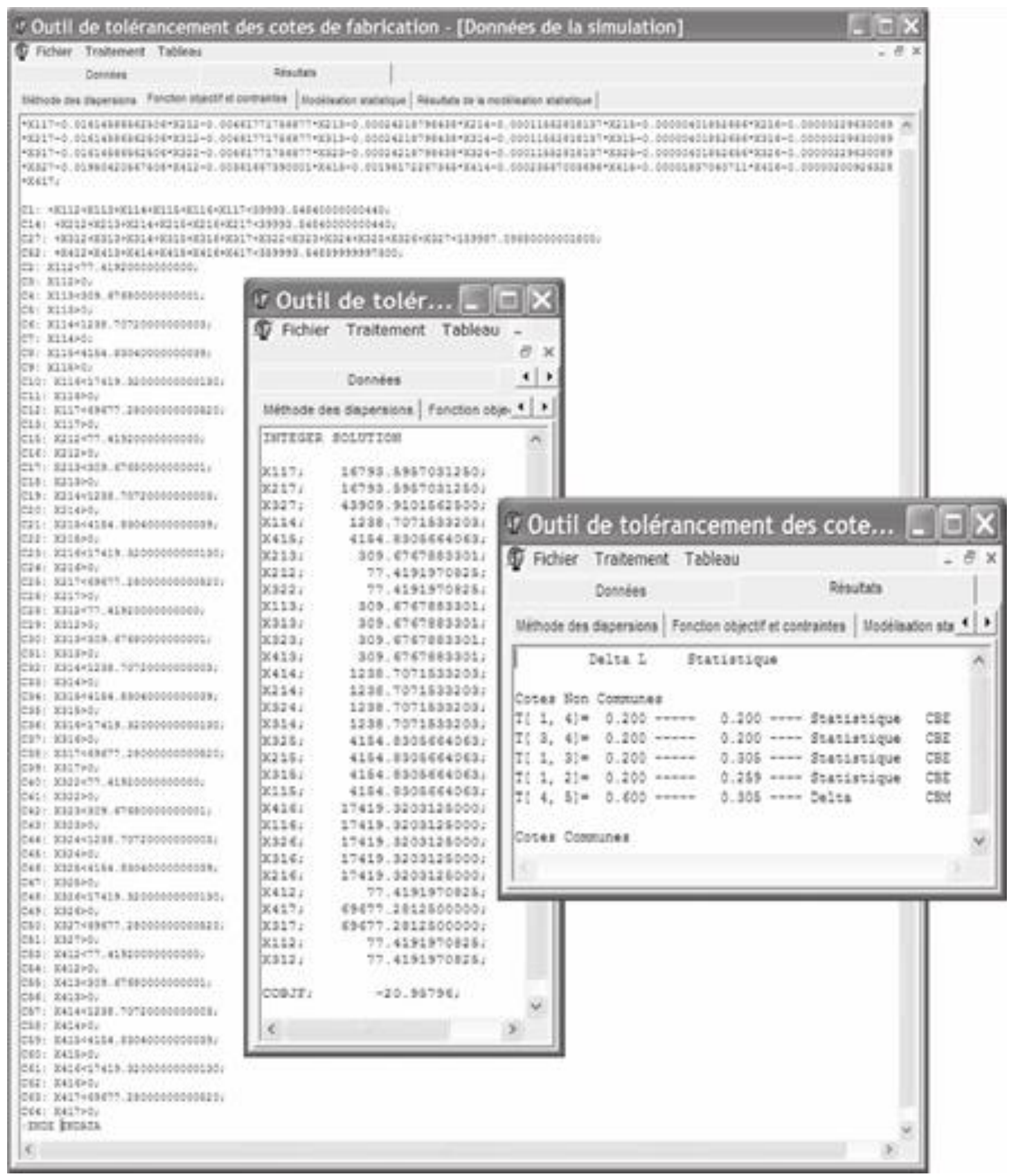

Figure 9. Statistical tolerance synthesis for the sample example.

performs a global optimization of the tolerances for the whole manufacturing process plan. This global optimization solves the whole process plan taking into account interrelated manufacturing chains with common manufacturing dimensions. This case is illustrated for the second sample process plan example of figure 10. The screens of figure 11 give the simulation process plan data and the optimization results with the Dl method. This figure shows from the extracted manufacturing chains that there are three common manufacturing dimensions $\mathrm{CF}_{2-3}, \mathrm{CF}_{2-9}$ and $\mathrm{CF}_{2-10}$ in the process plan. The screens of figure 12 give the results of the simulation module based on the newly 
Table 3. Manufacturing tolerances [mm] for the sample example.

\begin{tabular}{lcc}
\hline $\begin{array}{l}\text { Manufacturing } \\
\text { tolerance }\end{array}$ & $\begin{array}{c}\text { Distribution } \\
\text { by the Dl method }\end{array}$ & $\begin{array}{c}\text { Statistical } \\
\text { synthesis }\end{array}$ \\
\hline $\mathrm{T}_{\mathrm{CF}_{3 \ddot{y} 4}}$ & 0,200 & 0,200 \\
$\mathrm{~T}_{\mathrm{CF}_{1 \ddot{y} 3}}$ & 0,200 & 0,305 \\
$\mathrm{~T}_{\mathrm{CF}_{1 \ddot{y} 2}}$ & 0,200 & 0,259 \\
$\mathrm{~T}_{\mathrm{CF}_{1 \ddot{y} 4}}$ & 0,200 & 0,200 \\
$\mathrm{~T}_{\mathrm{CF}_{4 \ddot{y} 5}}$ & 0,200 & 0,305
\end{tabular}

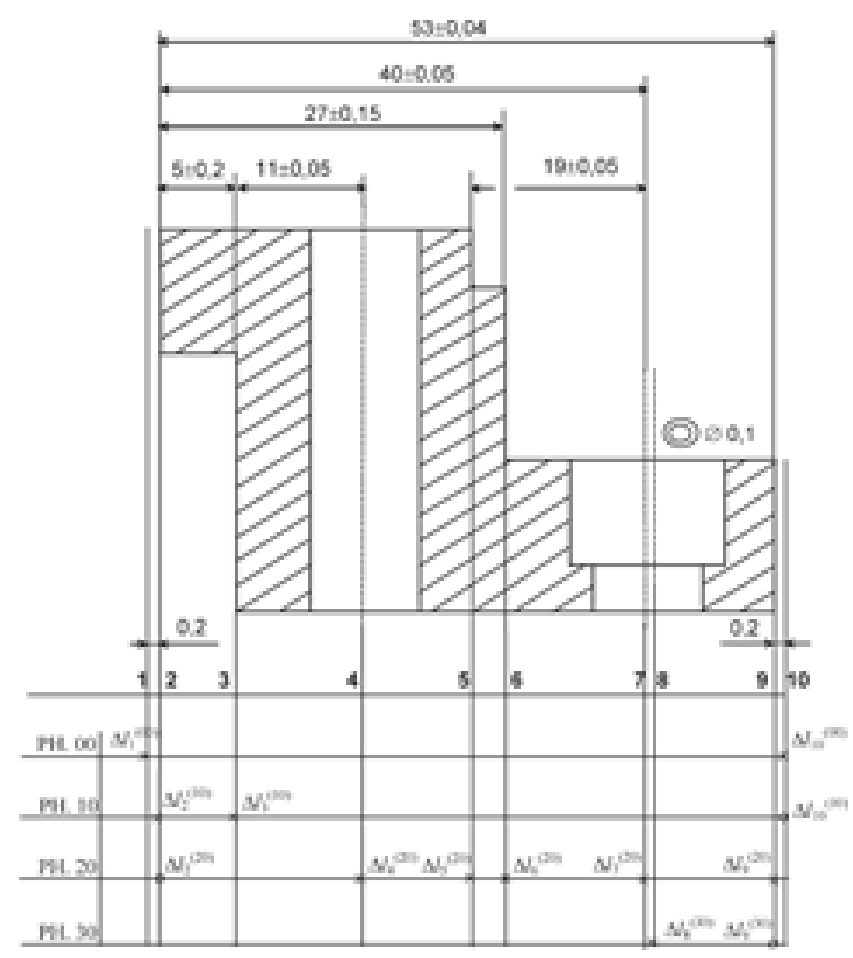

Figure 10. Sample example with interrelated manufacturing chains.

developed statistical tolerance synthesis model where the optimization is performed without fixing any of these common manufacturing tolerances.

\section{Conclusions}

This paper presents a new procedure for the optimization of manufacturing tolerances in computer aided process plan simulation. This procedure is based on a statistical tolerance synthesis model which glabally distributes the functional design and process tolerances among all the manufacturing dimensions involved in the manufacturing dimension chains of the process plan. The model uses the data extracted from the process plan matrices using the dispersions (Dl) method. The optimization objective function of the model is constructed from the identified manufacturing dimensions and the constraints of the model are constructed from the extracted dimension chains. The cost-tolerance data is used to assign the largest tolerance to the most diffi cult manufacturing dimension to process and so on. The model integrates into its definition the statistical aspects of manufacture and assumes that all the manufacturing dimensions are normally distributed. This RSS model which is reliable to $99,73 \%$ requires a severe strategy of inspection of the manufactured parts. However, the model can on the one hand be adapted to take into account general non-normally distributed dimensions by keeping the statistical (standard deviation) parameters into its definition. On the other hand, the model can be reformulated as a worst case model in order to perform a global arithmetic distribution of the functional design tolerances among the components of all the manufacturing dimension chains of the process plan. Since the arithmetic distribution remains the surest way for a safe optimization and simulation, both the arithmetic and statistical tolerance synthesis are made available for use by the process engineers in the developed computer aided process plan simulation module.

\section{Nomenclature}

s: $\quad$ standard deviation for a manufacturing dimension

Dl: dispersion of a machined surface or a positioning surface

a: $\quad$ second limit surface of a dimension

d: $\quad$ first limit surface of a dimension

i: $\quad$ index for a surface; index for a manufacturing dimension

$\mathrm{j}$ dimension chain or tolerance chain

$\mathrm{k}$ : linear segment in the tolerance-cost curve for a dimension

1: number of segments in the tolerance-cost curve for a dimension

$\mathrm{m}$ number of common tolerance components in the process plan

$\mathrm{n}$ number of tolerance components in the tolerance chain

p: manufacturing phase or operation

s: linear segment in the tolerance-cost curve for $\mathrm{s} 5 \mathrm{k}$

t: $\quad$ common manufacturing dimension

w: number of manufacturing dimensions or tolerance chains

C: $\quad$ cost factor of tolerance

$\mathrm{K}$ : $\quad$ statistical parameter corresponding to the level of confidence

$\mathrm{T}$ : $\quad$ tolerance 


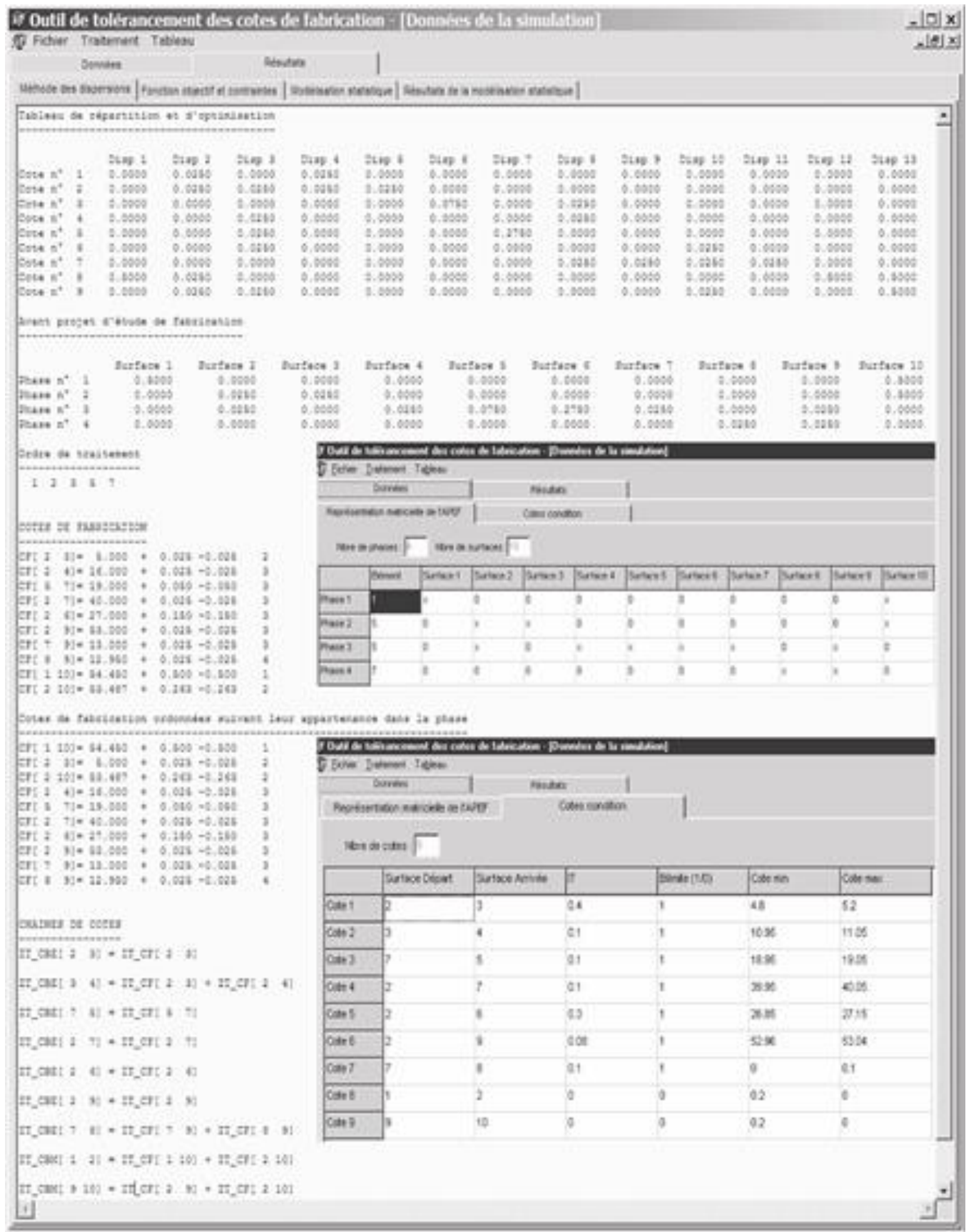

Figure 11. Simulation data and Dl optimization results for the second example. 


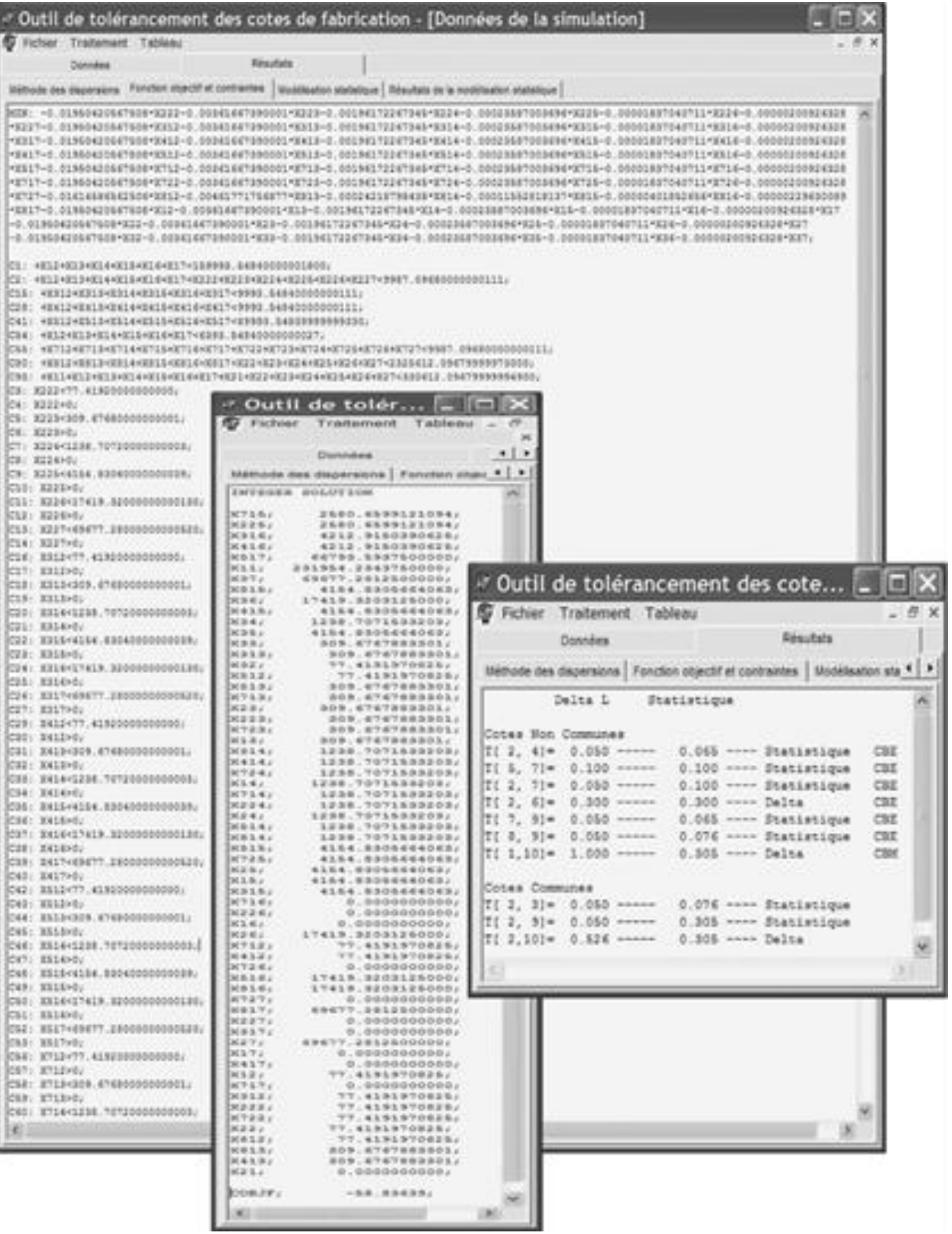

Figure 12. Simplex data and statistical synthesis results for the second example. 
$\mathrm{X}$ : linear tolerance segment variable in the tolerance-cost curve

V: $\quad$ slope of linear tolerance segment in the tolerance-cost curve

CBE: functional design dimension

CBM: process minimal material removal or chip dimension

CC: design or process dimension condition

CF: manufacturing dimension

PP: $\quad$ process plan

\section{References}

Cheikh, A., Combined statistical optimisation linear programming and mixed integer linear programming tolerance analysis and synthesis models. Les Annales Maghrébines de l'Ingénieur, 1998, 12 (Hors série), pp. 743-748.

Dong, Z. and Soom, A., Automatic optimal tolerance design for related dimension chains, Manufacturing Review. American Society of Mechanical Engineers, 1994, 3/4, pp. 262-271.
Duret, T., Simulation de gamme d'usinage. Revue de l'Ingénieur et du Technicien de L'enseignement Technique, 1981, 229, pp. 34-37.

Fainguelernt, D., Weill, R. and Bourdet, P., Computer aided tolerancing and dimensioning in process planning. Annals of the CIRP, 1986, 35(1)

$$
\text { pp. 311-315. }
$$

Hamou, S., Cheikh, A., Linares, J.M. and Benamar, A., Machining dispersions based procedures for computer aided proces plan simulation. Int. J. Comput. Integ. Manuf., 2004, 17(2), pp. 141-150.

Halevi, G. and Weill, R.D., Principles of process planning a logical approach, 1995 (Chapman and Hall: London).

Marty, C. and Linares, J.M., Industrialisation des produits mécaniques: conception et industrialisation, 1994 (Hermes, Tome1: Paris).

Murty, K.G., Linear programming, 1983 (John Willey \& Son: New York).

Peat, A.P., Cost reduction charts for designers and process engineers, 1968 (Machinary Pub Co.: London).

Tinel, J. and Dardy, F., Communiquer en conception mécanique, 1991 (Coter-tolérancer, Foucher: Paris).

Weill, R., Integrating dimensioning and tolerancing in computer aided process planning. Robotics and Computer Integrated manufacturing, 1988, 4(1/2), pp. 41-48. 